\title{
TITLE:
}

\section{Chimpanzees grooming an unknown monkey}

$\operatorname{AUTHOR}(S)$ :

Bakuneeta, Christopher

CITATION:

Bakuneeta, Christopher. Chimpanzees grooming an unknown monkey. Pan Africa News 1996, 3(2): 10-10

ISSUE DATE:

1996-12

URL:

http://hdl.handle.net/2433/143340

RIGHT:

Copyright (C) Pan Africa News. 


\title{
Chimpanzees grooming an unknown monkey
}

\author{
Christopher Bakuneeta \\ Budongo Forest Project, Masindi
}

At Kaniyo-Pabidi Ecotourism Site, which is $29 \mathrm{~km}$ on the road to Murchison Falls National Park, chimpanzees are being habituated for tourism. It has been confirmed that a group of chimpanzees is always moving with an unknown species of monkey. Budongo Forest has 5 species of diurnal primates: the chimpanzee (Pan troglodytes schweinfurthii), the blue monkey (Cercopithecus mitis stuhlmannii), the black-cheecked white-nosed monkey (C. ascanius ascanius), the black and white colobus (Colobus guereza occidentalis) and the olive baboon (Papio anubis). The monkey that is always moving with chimpanzees is none of these.

Any time you encounter the Kaniyo-Pabidi group of chimpanzees the unknown species of monkey is there. Not only does it feed with the chimpanzees, the latter also groom it and it also grooms them.

I would like to know from other primatologists whether similar cases have been seen elsewhere. My guess is that the monkey is a hybrid of two of the monkeys mentioned above. But I may be wrong. And why does it move with chimpanzees?

On this note I am encouraging primatologists and any one interested to come and track chimpanzees at this site and you might be lucky enough to see this strange monkey. You need $\$ 15$ per night. (You must also pay for your own food.) Only camping facilities are available.

Note: Dr. Bakuneeta was planning to track this monkey in mid-October 1996 and take photographs and some hairs (if possible) so that the taxonomy of the monkey can be traced. He asks those who are interested in this matter to write to him using the following address: Budongo Forest Project, P.O. Box 362, Masindi, Uganda. 